\title{
KANDUNGAN SENYAWA KIMIA DAN BIOAKTIVITAS DARI SELAGINELLA DOEDERLEINII HIERON
}

\author{
Khoirul Ngibad \\ Fakultas Ilmu Kesehatan, Universitas Maarif Hasyim Latif Sidoarjo \\ *Corresponding Author Email : khoirul_ngibad@dosen.umaha.ac.id
}

\begin{abstract}
Cakar ayam (Selaginella doederleinii Hieron) is a wild plant that has potential as a herbal medicine. This review aims to examine phytochemical studies and pharmacological investigations of the herb "Selaginella doederleinii Hieron". Available information on phytochemical content and pharmacological studies from Selaginella doederleinii Hieron were collected from electronic search (DOAJ, PubMed, ScienceDirect, Google Scholar and Spingerlink). The results of this article review showed that the most of the chemical content contained in the plant Selaginella doederleinii Hieron is class of flavonoid and alkaloids compounds. Several studies have reported that Selaginella doederleinii Hieron can be potent as an antioxidant, antitumor, anticancer, antibacterial, and antiviral. The review of this article is expected to serve as a source of reference for further exploration needed for the development of Selaginella doederleinii Hieron into a standardized herbal medicine or phytopharmaca.
\end{abstract}

Keywords : Selaginella doederleinii Hieron, phytochemical, antioxidant, antibacterial, anticancer

\section{PENDAHULUAN}

Indonesia mempunyai kekayaan sumber daya alam, yang salah satunya berasal dari tanaman. Masyarakat Indonesia telah menggunakan sekitar tujuh ribu tanaman dari 283 spesies sebagai jamu yang didaftarkan ke Badan Pengawas Obat dan Makanan (BPOM) Republik Indonesia (Komala et al. 2016). Salah satu tanaman yang berpotensi dijadikan obat herbal adalah cakar ayam (Selaginella doederleinii Hieron) yang merupakan tanaman liar dan banyak tumbuh di Indonesia. Selaginella doederleinii Hieron dari family Selaginella Pteridophyta, juga telah digunakan dalam pengobatan tradisional Tiongkok, yang tumbuh di dataran rendah terutama di Gui Zhou, Yun Nan, Si Chuan, Chong Qing dan Guangxi dari China (Gang, Hua, Lian, Mei, 2017). Dalam review artikel ini, akan ditelusuri mengenai kandungan fitokimia dan efek farmakologis dari tanaman Selaginella doederleinii Hieron.

\section{METODOLOGI PENELITIAN}

Sumber data yang digunakan sebagai referensi dalam review artikel ini diperoleh dari internet, yaitu : berupa artikel penelitian baik yang dipublish di jurnal ilmiah nasional maupun internasional. Pencarian istilah yang dilakukan untuk memperoleh referensi jurnal ilmiah adalah dengan menggunakan kata-kata atau frase kata, atau kalimat yang berhubungan dengan Selaginella doederleinii Hieron, yaitu journal of Selaginella doederleinii Hieron, distribution 
of Selaginella doederleinii Hieron, morphological of Selaginella doederleinii Hieron, chemical constituents of Selaginella doederleinii Hieron, pharmacology activity of Selaginella doederleinii Hieron, dan chemical compunds of Selaginella doederleinii Hieron.

Strategi dalam pencarian artikel penelitian dalam suatu jurnal ilmiah adalah melalui penggunaaan google chrome dengan beberapa situs search engine yaitu google.com, google scholar, doaj.com, science direct, PubMed, Scopus, dan Springer Link.. Kemudian artikelartikel yang telah disebutkan dan sesuai dengan keyword yang dikehendaki, maka artikel tersebut didownload lalu disimpan untuk dilakukan skrining dan menjadi referensi review artikel.

\section{STUDI FITOKIMIA}

Penelitian mengenai studi fitokimia yang bertujuan untuk mengetahui kandungan kimia dari tanaman Selaginella doederleinii Hieron sudah cukup banyak dilakukan dari berbagai Negara. Dalam studi fitokimia, para peneliti lebih memfokuskan adanya kandungan senyawa kimia aktif yang dapat berpotensi sebagai obat herbal. Selaginella doederleinii Hieron (Selaginellaceae) telah digunakan sebagai obat herbal tradisional untuk mengobati kanker dan penyakit kardiovaskular di Asia Tenggara. Hasil elusidasi struktur menggunakan spektroskopi UV, FT-IR, NMR menunjukkan bahwa Selaginella doederleinii Hieron mengandung senyawa biflavonoid baru, 2,3-dihydrorobustaflavone 7,7"-dimethyl ether (Gambar 1 (1)), 2,3dihydrorobustaflavone 7,4',7"-trimethyl ether (Gambar 1 (2)), dan 2",3"dihydrorobustaflavone 7,4',7"-trimethyl ether (Gambar 2) (Han et al. 2013).

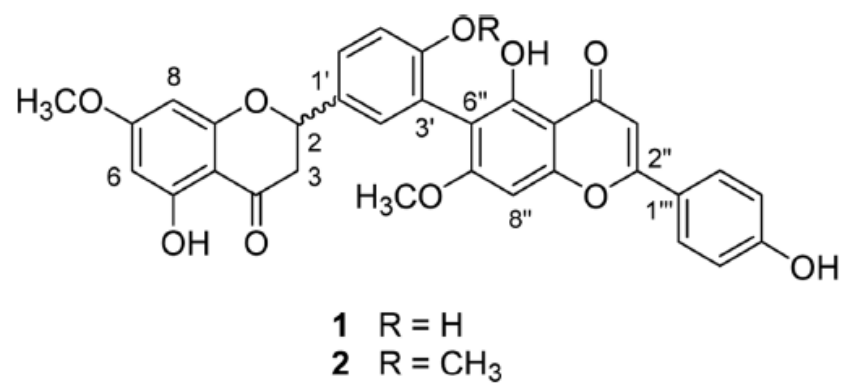

Gambar 1. Struktur kimia 2,3-dihydrorobustaflavone 7,7"-dimethyl ether (1) dan 2,3dihydrorobustaflavone 7,4',7"-trimethyl ether (2)

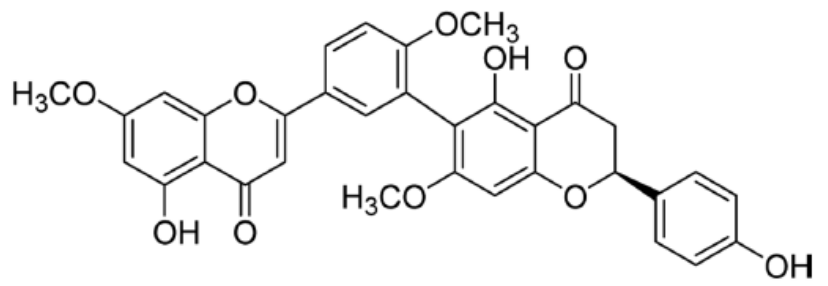

3

Gambar 2. Struktur kimia 2",3"-dihydrorobustaflavone 7,4',7"-trimethyl ether 
Pemisahan dan pemurnian ekstrak etil asetat dari Selaginella doederleinii Hieron dilakukan menggunakan teknik kromatografi. Dua puluh senyawa berhasil diperoleh dari ekstrak tersebut. Struktur senyawa yang diperoleh antara lain : myristic acid, $\beta$-Citronellol, palmitic acid, stearic acid, $\beta$-sitosterol, physcion, $3 \beta$ Acetoxysitost-5-en-7-one, emodin, chrysophanol, apigenin, amentoflavone, robustaflavone 7,4',7"-o-trimethyl ether, heveaflavone, podocarpusflavone A, robustaflavone 4',4"'-o-dimethyl ether, robustaflavone 4'o-methyl ether, adenosine, ferulic acid, syringate dan vanillic acid (Brad et al. 2017). Ekstrak etanol $75 \%$ dari Selaginella mengandung senyawa doederflavones A, doederflavones $B$, unciflavones $E$, unciflavone $D$, unciflavone $F$, 6-(2-hydroxy-5-carboxyphenyl)-apigenin, apigenin, kaempferol, isoschaftoside, schaftoside, chromone, dan 2, 6, 8-trimethylchromone (Sivaraman et al. 2013).

Sebelas senyawa fenolik juga berhasil diisolasi dari ekstrak etanol Selaginella doederleinii Hieron. Senyawa-senyawa tersebut adalah lima lignan: (-) - lirioresinol A, (-) lirioresinol B, (+) - wikstromol, (-) - nortracheloside, (+) - matairesinol, dua fenilpropanon: 3hidroksi 1-3-metoksi-4-hidroksifenil) -propana, 3-hidroksi-1 (3,5 - dimetoksi-4-hidroksifenil) -propana, dan empat biflavonoid: amentoflavon, 7,7 "' - di--methylamentoflavon, 7,4 ', 7' ', 4' " - tetra-O-methylamentoflavon, dan heveaflavon (Lin et al. 1994).

Almeida et al melakukan review kandungan senyawa dalam Selaginella doederleinii Hieron, yang meliputi : Hordenine, Hordenine-[6-O-(4-hydroxy-cinnamoyl)- $\beta$-D-glucosyl](1,3)- $\alpha$-L-rhamnoside, Hordenine-O-(6"'-O-trans-cinnamoyl)-4'-O- $\beta$-D-glucopyranosyl- $\alpha-L$ rhamnopyranoside, Hordenine-O- $\alpha$-L-rhamnopyranoside, $\quad N$-methyltyramine-O- $\alpha-L$ rhamnoside, Isopimpinellin, 7,7"'-Di-O-methyl-amentoflavone, 4',4"',7,7"'-Tetra-O-methylamentoflavone, dan Apigenin (Almeida et al. 2013).

\section{STUDI FARMAKOLOGI}

Efek farmakologi dari Selaginella doederleinii Hieron juga sudah cukup banyak diteliti. Beberapa studi farmakologi yang sudah dikaji meliputi : antioksidan, antitumor, antikanker, antibakteri, dan antivirus. Studi farmakologi tersebut kebanyakan masih dalam tahap uji secara in vitro dan sangat sedikit yang diuji secara in vivo terhadap hewan uji coba.

\section{Antioksidan}

Penelitian mengenai aktivitas antioksidan dari Selaginella doederleinii Hieron dilakukan secara in vitro. Dalam review ini, belum ditemukan studi aktivitas antioksidan secara in vivo sehingga perlu dilakukan studi aktivitas antioksidan secara in vivo untuk melengkapi database efek farmakologi dari Selaginella doederleinii Hieron. Sembilan senyawa biflavone (amentoflavone, robustaflavone, 4'-methoxy robustaflavone, podocarpusflavone, hinokiflavone, ginkgetin, dan heveaflavone) menunjukkan aktivitas antioksidan yang baik menggunakan metode DPPH (Yao et al. 2017). Ekstrak etil asetat dari Selaginella doederleinii Hieron juga berpotensi sebagai sumber bioaktif alami yang mudah didapat dari alam. Aktivitas ekstrak tersebut dikaitkan dengan kandungan fenoliknya, terutama amenoflavon, hinokiflavon dan robustaflavon (Gang et al. 2016).

Uji antioksidan terhadap kandungan fenol dan biflavonoid dari Selaginella doederleinii Hieron dilakukan menggunakan metode 2,2-diphenyl-1-picrylhydrazyl (DPPH) dan 2,2'azinobis-3 etilbenzionoolin-6-sulfonat (ABTS). Diantara lima fraksi, ekstrak etil asetat 
menunjukkan aktivitas peredaman radikal DPPH sebesar $85,77 \%$, aktivitas peredaman radikal ABR sebesar 90,39\%, khelasi efek ferrous ion sebesar 82,51\% dan daya reduksi sebesar 1,227 (Gang, Hua, Lian, Mei, Mei, 2017). Ekstrak flavonoid total dari Selaginella doederleinii Hieron yang diuji menggunakan 2,2-diphenyl-1-picryl-hydrazyl (DPPH) juga menghasilkan aktivitas antioksidan yang baik (Lian et al. 2013).

\section{Antitumor}

Studi aktivitas antitumor dari Selaginella doederleinii Hieron juga sudah dikaji. Ekstrak etil asetat dari Selaginella doederleinii Hieron memiliki aktivitas antitumor yang cukup besar secara in vitro dan in vivo pada sel normal dan dapat menyebabkan apoptosis sel. Mekanisme tumorigenesis dan apoptosis sel karsinoma yang disebabkan oleh ekstrak etil asetat dapat dikaitkan dengan penurunan rasio tingkat bcl-2 dan bax mRNA, mengaktifkan caspase-3, menekan survivin, dan menurunkan ekspresi gen COX-2, 5-LOX, FLAP, dan 12-LOX mRNA (Wang et al. 2015). Zat bioaktif utama ekstrak Selaginella doederleinii Hieron sebagian besar bersifat fenolik. Amentoflavon tidak hanya dapat secara efektif menghambat berbagai macam proliferasi sel tumor tetapi juga menginduksi apoptosis sel tumor dan diferensiasi (Gang et al. 2016). Di sisi lain, ekstrak etanol Selaginella doederleinii Hieron menunjukkan aktivitas penghambatan yang berbanding lurus dengan konsentrasi pada sel CNE-1, sementara tidak menunjukkan kecenderungan proporsional yang jelas sehubungan dengan sel C666-1 (Lian et al. 2013).

\section{Antikanker}

Selaginella doederleinii Hieron telah digunakan untuk pengobatan berbagai jenis kanker, terutama untuk karsinoma nasofaring, kanker paru-paru dan tumor trofoblastik. Ekstrak etil asetat dari Selaginella doederleinii Hieron menunjukkan potensi anti kanker yang baik (Sui et al. 2016). Dalam penelitian lain, ekstrak etil asetat juga menunjukkan sitotoksisitas yang ditandai terhadap A549 regangan sel, regangan sel 7721, garis sel Hela dan garis sel Eca-109 dengan nilai IC50 masing-masing 52,66, 66,20, 37,53 dan 62,09 $\mu \mathrm{g} / \mathrm{mL}$ daripada empat fraksi lainnya. Biflavonoid ditemukan berperan penting untuk efek antikanker. Ekstrak Selaginella doederleinii Hieron memiliki potensi sebagai bahan baku pengembangan obat antikanker oleh industri farmasi (Gang, Hua, Lian, Mei, Mei, 2017).

\section{Antibakteri}

Dalam review artikel ini, hanya ditemukan 1 artikel penelitIan mengenai studi aktivitas antibakteri dari Selaginella doederleinii Hieron. Fraksi ekstrak petroleum eter dari ekstrak kasar etanol Selaginella doederleinii Hieron menunjukkan zona penghambatan yang lebih efisien terhadap Bacillus subtilis, Staphylococcus aureus, Escherichia coli dan Pseudomonas (Gang, Hua, Lian, Mei, Mei, 2017). Dengan demikian, perlu dikaji lebih dalam mengenai aktivitas antibakteri dari Selaginella doederleinii Hieron.

\section{Antivirus}


Ekstrak flavonoid total dari Selaginella moellendorffii Hieron dan senyawa utamanya amentoflavon diselidiki melawan virus coxsackie B3 (CVB3) untuk mengetahui potensinya sebagai antivirus. Hasil penelitian menunjukkan bahwa uji antivirus baik secara in vitro maupun in vivo menggunakan tikus yang terinfeksi CVB3 secara efektif dapat diobati dengan ekstrak flavonoid total dari Selaginella moellendorffii Hieron (Yin et al. 2014).

\section{KESIMPULAN}

Selaginella doederleinii Hieron mengandung 2,3-dihydrorobustaflavone 7,7"-dimethyl ether, 2,3-dihydrorobustaflavone 7,4',7"-trimethyl ether, 2",3"-dihydrorobustaflavone 7,4',7"trimethyl ether, myristic acid, $\beta$-Citronellol, palmitic acid, stearic acid, $\beta$-sitosterol, physcion, $3 \beta$ Acetoxysitost-5-en-7-one, emodin, chrysophanol, apigenin, amentoflavone, robustaflavone, heveaflavone, podocarpusflavone A, robustaflavone 4',4'"'-o-dimethyl ether. Beberapa penelitian telah melaporkan bahwa Selaginella doederleinii Hieron dapat berpontensi sebagai antioksidan, antitumor, antikanker, antibakteri, dan antivirus. Meskipun demikian, eksplorasi tanaman Selaginella doederleinii Hieron pelu dikaji lebih mendalam agar berpotensi untuk dikembangkan menjadi obat herbal terstandar atau fitofarmaka.

\section{DAFTAR PUSTAKA}

Almeida, Jackson Roberto Guedes da Silva, Pedro Guilherme Sousa Sá, Larissa Alves Ribeiro de Oliveira Macedo, José Alves Siqueira-Filho, Viseldo Ribeiro Oliveira, and José Maria Barbosa-Filho. 2013. Phytochemistry of the Genus Selaginella ( Selaginellaceae). Journal of Medicinal Plants Research. 7 (25):1858-1868. https://doi.org/10.5897/JMPR12.1223.

Brad, Korbanjhon, Yan Zhang, Xu Yang, and Tianxin Wang. 2017. Identification of Chemical Constituents of Selaginella doederleinii Hieron. Advances in Engineering Research (AER), 143(143):455-459.

Gang, Wang, L I Sanhua, Zhou Honglian, and G U O Die. 2016. Comparison of Antioxidant and Anticancer of the Extracts from Various Habitats of Selaginella doederleinii. 5th International Conference on Environment, Materials, Chemistry and Power Electronics (EMCPE 2016) :785-790.

Han, Ah Reum, Na Youn Lee, Joo Won Nam, Adam Wiryawan, and Eun Kyoung Seo. 2013. Identification of a New Biflavonoid from Selaginella doederleinii Hieron. Bulletin of the Korean Chemical Society. 34(10) : 3147-3149. https://doi.org/10.5012/bkcs.2013.34.10.3147.

Komala, Lukiati, Hanny Hafiar, Priyo Subekti, Universitas Padjadjaran Bandung, Universitas Padjadjaran Bandung, and Universitas Padjadjaran Bandung. 2016. Jejaring Komunikasi Dalam Penyebaran Informasi Obat Herbal di Kalangan Pengguna. Jurnal Ilmu Komunikasi (J-IKA). 3(1):85-94.

Lian, Rong, Jing Li, Hui Min Ma, Guo Zheng Zhang, Xi Ai Guo, Xiao Li, and Jian Bin Yang. 2013. Effect of Ethanol Extract of Selaginella doederleinii Hieron on the Proliferation of Nasopharyngeal Carcinoma CNE-1 and C666-1 Cells. African Journal of Traditional, Complementary, and Alternative Medicines : AJTCAM / African Networks on Ethnomedicines.10(6) : 90-93.

Lin, Rui, Alexios-Léandros Skaltsounis, Elisabeth Seguin, François Tillequin, and Michel Koch. 1994. Phenolic Constituents of Selaginella doederleinii. Planta Medica. 60 (2):168-170. https://doi.org/10.1055/s-2006-959443.

Sivaraman, a, M Johnson, T Parimelazhagan, and V Irudayaraj. 2013. Evaluation of 
Antioxidant Potential of Ethanolic Extracts of Selected Species of Selaginella. Indian Journal of Natural Products and Resources 4 (3):238-244.

Sui, Y., S. Li, P. Shi, Y. Wu, Y. Li, W. Chen, L. Huang, H. Yao, and X. Lin. 2016. Ethyl Acetate Extract from Selaginella doederleinii Hieron Inhibits the Growth of Human Lung Cancer Cells A549 via Caspase-Dependent Apoptosis Pathway. Journal of Ethnopharmacology. 190 : 261 - 271. https://doi.org/10.1016/j.jep.2016.06.029.

Wang, Jia Zhi, Juan Li, Ping Zhao, Wen Tao Ma, Xie He Feng, and Ke Li Chen. 2015. Antitumor Activities of Ethyl Acetate Extracts from Selaginella doederleinii Hieron in vitro and in vivo and Its Possible Mechanism. Evidence-Based Complementary and Alternative Medicine. 2015. 1 - 9. https://doi.org/10.1155/2015/865714.

Yao, Hong, Bing Chen, Yanyan Zhang, Huigen Ou, Yuxiang Li, Shaoguang Li, Peiying Shi, and Xinhua Lin. 2017. Analysis of the Total Biflavonoids Extract from Selaginella doederleinii by HPLC-QTOF-MS and Its in vitro and in vivo Anticancer Effects. Molecules. 22(2) : 1 - 17. https://doi.org/10.3390/molecules22020325.

Yin, Dan, Juan Li, Xiang Lei, Yimei Liu, Zhanqiu Yang, and Keli Chen. 2014. Antiviral Activity of Total Flavonoid Extracts from Selaginella moellendorffii Hieron against Coxsackie Virus B3 In Vitro and In Vivo. Evidence-Based Complementary and Alternative Medicine. 2014 : 1-7. https://doi.org/10.1155/2014/950817. 